\title{
OCCUPATIONAL HEALTH HAZARDS IN HOSPITALITY INDUSTRY AND THEIR PREVENTION (REVIEW ARTICLE)
}

\author{
By \\ Samir AM \\ Department of Occupational and Environmental Medicine, Faculty of Medicine, \\ Cairo University, Egypt. \\ Corresponding author Samir AM; email: aishasamir@kasralainy.edu.eg
}

\begin{abstract}
Introduction: Hospitality industry offers employment to people with different personalities, background and skills through a wide diversity of different types of outlets services. Hospitality industry includes a wide range of tasks and jobs which pose different risks. The hospitality industry is a key provider of jobs around the world. The complexity of the sector makes it difficult to estimate an overview of the situation. A wide range of hospitality businesses are directly or indirectly dependent on tourism; lodging, transportation, travel and trips. More attention goes towards working in hotels and restaurant and to a lesser attention is given to supporting activities such as cleaning jobs and receiver services. The workforce in this sector is faced with a large number of physical, chemical, ergonomic and psychological risks. This review has addressed several important points about hospitality industry; sectors of hospitality industry, the important of hospitality industry worldwide and controls of risks that may happen at different workplace in the hospitality industry. It discusses the hazards that may occur in the latter. A risk assessment must be carried out on health hazards in hospitality industry. The risk assessment should identify risks and control them: including both engineering and organization so as to avoid or reduce the risk of injury or illness. This review focuses on effective control measures that protect workers from workplace hazards in hospitality industry. These measures help to avoid injuries, illnesses, and incidents, minimize or eliminate health risks. Also it helps employers to provide .workers with safe and healthful working conditions
\end{abstract}

Key words: Hospitality industry, Sectors of Hospitality Industry, Health Hazards, Prevention of hospitality hazards. 


\section{Introduction}

\section{1- Definition of Hospitality Industry}

Hospitality means: the friendly and generous receiving and excitement of guests, visitors, or strangers. The word "hospitality" is a Latin noun which means nursing home; it is well known as a house of rest for travelers and pilgrims. Hospice -a word that is clearly related to hospital-also referred to an early form of what we now call a nursing home (Oxford Dictionary, 1998). Hospitality includes not only hotels and restaurants, but it also refers to other kinds of businesses that give shelter or food or both to people away from their homes. Hospitality industry is a broad group of trades that gives services to customers. It focuses on their satisfaction. It acknowledges the needs of guests in a variety of establishments. Hospitality industry provides labour to people of different skills and backgrounds through a many outlets services. Hospitality includes direct operations and maintenance of facilities such as servers, housekeepers, porters, kitchen workers, management, marketing, and human resources (Peter, 2017).

\section{2- Sectors of Hospitality Industry}

The hospitality industry is a broad category of fields that includes transportation, lodging, theme parks, cruise line, travelling and tourism industry. There are five major sectors of the hospitality industry: food and beverages, lodging-accommodation, travel and tourism, entertainment and timeshare (Global Hospitality portal, 2016).

\subsection{Food and Beverages:}

The food and beverage industry consists of businesses that prepare food for customers, it is known as the food service industry. Food and beverage sector is the supreme in the hospitality industry. It includes something as simple as a small restaurant, a high-end restaurant and every catering establishment in between (Sally, 2017).

Food service industry as an important sector of the hospitality industry can be classified as:

\subsubsection{Quick-Service Establishments:} These are commercial foodservice restaurants that provide customers with snacks, drinks, and meals. They have fewer employees. It includes self-service as: McDonald's, Kentachy Fried Chicken (KFC), Pizza Hut.... etc. 
2.1.2 Catering Businesses: These provide food and beverage catering services for any special occasion from weddings to birthday parties.

\subsubsection{Full-Service Restaurants:} These are the typical restaurants which provide meals, drinks, and other food services. At a restaurant, you seat at table and a waiter takes your food order. They include fine dining, casual dining and themed restaurants. Food and catering are crucial for the hospitality industry. It begins with food production and ends by food representation on the eating tables with storage and cooking steps resting in between. Many hotels and restaurants serve natural organic food. Food Management: It includes production of food, storage and food transportation. It also focusses on food representation to improve hospitality experience. Restaurant Management: is a science that is taught in colleges nowadays, offering proper skills to manage a restaurant, food, beverages, and maintain a quality representation of food (Global Hotel Industry, 2018).

\subsection{Lodging-Accommodation:}

Accommodation is one of the sectors of the hospitality industry. It starts from bed and breakfast enterprises and hotels to other facilities that offer lodging services including youth and elder hostels, campgrounds and motels. It provides a place for people to sleep overnight. Lodging, suites and resorts are forms of hotel and accommodation (Global Hospitality portal, 2016).

\subsection{Travel and Tourism:}

The most important part of the hospitality industry is travel either for business or leisure and tourism. Many people consider tourism synonymous with hospitality and not as a different sector of the hospitality industry. This requires customer focus, relationship management, and other integrated marketing skills for its running and expansion.

\subsection{Entertainment:}

Recreation is what people do at rest, relaxation, and enjoyment. Entertainment businesses provide shows such as movie or theater. There are attraction places of special interest such as zoos and museums, spectator sports and participatory sports. They are all parts of the recreation business (Sally, 2017).

\subsection{Timeshare:}

Timeshare is an emerging sector of the hospitality industry. It is vacation ownership of a place; either individuals 
or parties, own a place for a specific time period during the year. Nowadays there is a raise interest of hospitality enthusiasts for timeshare (Peter, 2017).

\section{The Importance of Hospitality Industry Worldwide}

Tourism is one the largest industries in the world, comprising 1,186 billion international tourists in the world and accounting for almost $10 \%$ of World. Europe had the highest occupancy rate in 2016 at 70.4 percent, closely followed by the Asia Pacific region at 69 percent. In the same year, the Middle East and Africa were the most expensive region for hotels with an average daily rate of 149.02 U.S. dollars. The Asia Pacific was the cheapest region for the last two years. (Global Hotel Industry, 2018).

Hospitality and restaurant industry is a varied and highly competitive industry. There is competition among different enterprises; coffee shops, pizza restaurants, and quick-service restaurant chains. Luxury fine-dining restaurants offer to the customer a vast variety of choices. Most famous in the industry include McDonald's, coffee house chain Starbucks and Domino's Pizza in the pizza chain segment (Global Travel and Tourism Industry, 2018).
Hospitality industry is considering one of the most important providers of jobs around the world. It provides jobs for over 235 million people and 8 percent of all the people employed on a global scale in 2010. The growth of the revenue that has seen since 2009, meant increases in people employed in this industry (Travel, Tourism and Hospitality, 2018).

\section{Hazards in Hospitality Industry and Prevention}

\subsection{Hazards are categorized} according to type of the work:

Hazards in hospitality industry are divided according to type of work into housekeeping, food and beverages services, storage and receiver.

\subsubsection{Housekeeping/cleanup workers:}

There is an increase in the injury rate among hotel workers than other service sectors. Repetitive motion injuries (RMIs); sprains/strains are about 40\% in housekeeper injuries due to: cleaning mirrors, lifting mattresses and pushing carts weighing more than 300 pounds. According to California Workers' Compensation Information System (WCIS) data, 2016; falls, slips, and trips contribute to $20.5 \%$ of the injuries 
among hotel housekeepers which are the main preventable causes of injuries. These injuries usually happen within the first six months of employment. During the first two years of employment, $80 \%$ of all employee injuries occur.

To reduce injuries, we have to train staff to use ergonomic techniques as follows:

Always ask for help, not try to rotate or flip a mattress on your own.

$>$ Use a mattress lifting device when making bed.

$>$ An extension pole to clean a floor or bath must be used during cleaning when you are standing to prevent bending.

$>$ A step ladders must be used so as not to stand on tub or toilet.

$>$ Linen carts must not be overloaded with dirty linens.

$>$ Always check vacuum and empty it regularly so as not to be heavy.

> Use gloves to protect hands and safety goggles to protect eyes.

\subsubsection{Food and beverages} services/kitchen workers:

These groups of workers are exposed to hazards e.g. wet and slippery floors, deep fry equipment, hot cooking equipment and oil, sharp objects and unguarded machine used in food preparation

Work-related upper limb disorders (WRULDs) are consider the main causes of occupational illness in the food and drink industries. They usually result from poor work organization. Occupational asthma in kitchen is usually caused by inhalation of bakery and grain dusts. Rhinitis occurs due to exposure to irritant dusts such as spices, bakery and grain dusts. Contact with foodstuffs and handwashing chemicals can result in Occupational dermatitis. Noise-induced hearing loss may happen in places, where noise levels exceed 85 dB (A) (Sally, 2017).

Food Safety and Hygiene is crucial for the wellbeing and safety of the customers in food restaurants. A food handler is a person who handles food or surfaces that come into contact with food. Food business is involved in food preparation, cooking, production, display, packing, storage or service. It is very important for the food handler to know how to handle and process food by applying standards of food safety procedures and practices (Hospitality, 2014). 


\subsubsection{Storage and receiver} workers are exposed to hazards as: lifting, carrying, pushing, shiftwork, workload, low payment, insecurity, violence and harassment (Hospitality, 2014).

\section{2-Types of hazards:}

\subsubsection{Ergonomic Hazards:}

Many of the activities in hospitality industry include manual handling. Activities like, making beds delivery or the collection of plates, tables and drink trays are common in hospitality industry. Manual handling always causes pain and discomfort and can lead to long term illness. Workers can leave their jobs. They may be unable to work at all. Manual handling poses a risk or ergonomic hazard in different activities as pushing, pulling, lifting, carrying, or moving a load, where the characteristics of the load are unfavorable. The worker must avoid or reduce the need for such manual handling when possible, especially when the manual handling of loads involves a risk of injury. Over one-third of all reported incidents in the hospitality sector are manual handling. Muscle strains and sprains in the neck and limbs represent most of the injuries. Injuries may result in surgery or lifelong disability affecting the worker's career and social life. Workers under the age of 18 are at greater risk; their bodies are still developing, so they may suffer a permanent injury. Injury usually develops gradually over a period of time (Work Safe, 2014).

Focused on ergonomic controls, manual handling training to the working staff is an approach to reducing the risk of injury. Risk assessment, which is carried out on all manual handling process to avoid or reduce the risk of injury, should identify risks and controls them: including both engineering and organizational actions. This must be done to all working staff as follows: (Work Safe, 2009).

$>$ Manual handling should be limited so work must be organized.

$>$ Use available mechanical equipment e.g. hoists, trolleys, step ladders etc.

$>$ Assess before handling. Push rather than pull. Keep walkways clear.

> Use team's lifts where appropriate and break up large load.

$>$ Reduce repetitive or sustained bending, twisting and reaching whenever possible.

4.2.2 Safety measures for Hazards prevention and control: 


\subsubsection{Slips, trips and falls:}

High proportion of injuries in the hospitality industry includes slips, trips and falls. Injuries as fractured bones, muscle strains, sprains, cuts and abrasions and in extreme cases, head injury are results of slips, trips and falls. They may also result in an absence of more than one month from job. Slips occur by the presence of substances such as water, grease or oil, on the floor arising from work or in some cases the weather. Trips can occur as result from discard work items as electric cables or air hoses, curled-up carpets, uneven floor surface (Wayne, 2015). The risk of injury as a result of slips, trips and falls can be reduced by:

Keep stairs and floors clean and dry regularly. Spills must be cleaned immediately.

$>$ Put warning signs around spills or wet floors.

$>$ Know the procedures for cleaning spilled substances.

$>$ Ensure power cords are not placed across walkways.

\subsubsection{Machinery related} hazards:

In the hospitality industry, both powered and non-powered machinery are used. Cutters, slicers, mincers and knives are also used. Potential hazards associated with machinery are the result of; power source of equipment (e.g. electricity), moving parts (e.g. guarding), use of pressure equipment (e.g. espresso machines), noise and hazardous substances (e.g. fumes). Using or cleaning machinery/ equipment may result in workers' injuries. As a result of coming into contact with moving parts or being trapped in between, workers may be injured. Guarding can protect workers from serious cuts, crushing injuries, fractures and amputations. Injuries can be reduced through the following: (Srivastava, 2017).

$>$ Ensure that machines have safeguards and checking guarding is in place before operation.

$>$ Keeping equipment clean and in good working order, turning off equipment prior to cleaning, replacing all guards after cleaning is complete.

$>$ Unplug the mixer before inserting or ejecting beaters.

$>$ Take care to keep spoons, rubber spatulas, or fingers away from 
moving beaters.

$>$ Grasp the plug end not the cord, when plugging in or unplugging an electrical appliance,

Avoid the use of extension cords. Electric circuits must not be overload.

\subsubsection{Fire:}

The main causes of fires in the kitchen are electrical faults in wiring, lights and equipment, fat burning and grease flare-ups in cooking appliances. In a kitchen or restaurant area, there are classes of fire hazards: Class A includes wood, paper, fabric or cardboard, Class $\mathrm{B}$ includes flammable liquids, gases or grease, Class $\mathrm{C}$ includes electrical equipment and circuits. Portable fire extinguishers are labelled with A, B, C or a mixture. Class $\mathrm{K}$ involves fires that result from animal fat in the cooking of grease. Different fire extinguishers are used for these kinds of fires, which are typically located in restaurant or kitchen (Safe Hospitality, 2014).

The risk of fire measures should be reduced by as follows:

Ensure that electrical systems are regularly checked and errors reported and promptly fixed.
$>$ Regular inspection and maintenance by qualified persons of appliances is necessary.

$>$ Perform regular checks of automatic equipment for fire detection.

$>$ Ensure that all escape methods are properly maintained and kept free, accessible and easy to open.

$>$ Make sure the fire alarm is heard in all parts of the building, including the stores areas.

$>$ Never put a fire extinguisher that's been used back in place (even if it still feels heavy).

\subsubsection{Burns:}

Around 14 per cent of restaurant accidents lead to burns and scalds. Spilling or splashing of hot liquids, and contact with hot surfaces are the most common causes. Food can be served on heated plates or in skillets while it is hot (Sarah et al., 2018).

The risk of burns is reduced by the following:

$>$ Warn your guests about hot dishes or hot fillings in food, or about extremely hot liquids.

$>$ Utensils should be dried thoroughly before using them with hot oil. 
> Lower food and utensils slowly into hot oil. Use potholders.

$>$ Make sure the handles of pots and pans do not stick out from counters or stoves.

$>$ Open lids away from you to allow steam to escape.

$>$ Avoid burning of steam on the face, hands and arms.

\subsubsection{Chemicals Hazards:}

The hospitality industry uses various forms of dangerous cleaning chemicals including washing-up liquids, dishwasher detergents, drain-cleaning materials, oven cleaners, disinfectants, toilet cleaners, and bleach. $\quad \mathrm{T} \quad \mathrm{h} \quad \mathrm{e}$ most common threats are mostly through contact with the skin or eyes. Cleaning chemicals are corrosive so when splashed onto the body can cause skin and eye burns. Some chemicals cause irritation to skin. Others may cause dermatitis. Breathing of cleaning chemicals during work may lead to asthma especially in sensitized workers. Without adequate ventilation, some cleaning agents can cause breathing problems if used onto hot surfaces, for example oven cleaner.

Upon handling cleaning chemicals, touching the face, eyes, skin may cause irritation, inflammation or chemical burns. Adverse chemical reactions may also occur when cleaning agents are combined, for example, toxic gases will be emitted by cleaning products containing bleach mixed with acidic toilet cleaners or ammonia. Other hazards are derived from unintended splashes to the skin and eyes as chemicals are being poured from one container into another.

The risk of exposure to such chemicals could be reduced by the following: (Work Safe, 2009).

$>$ List all the dangerous chemicals that are being used.

$>$ Use the manufacturers' approved personal protective equipment.

$>$ Read the chemicals accompanying labels and safety data sheets (SDSs).

$>$ Follow the procedures of safe work practice. Store chemicals and write warning signs in a properly ventilated, locked area. Never combine chemicals for cleaning.

\subsubsection{Physical Hazards:}

\subsubsection{Hot working conditions:} may lead to heat-related illness found in kitchens. It occurs when the body can't lose heat quickly enough to maintain 
a steady core body temperature. Heat exposure can worsen certain medical conditions such as high blood pressure or cardiac problems. It can lead to heatrelated diseases like prickly skin, heat exhaustion (fainting), or heat cramps. It is important for exposed workers to avoid suffering from a heat-related disease (Hospitality Industry, 2008).

$>$ Wear comfortable shoes. Drink water in a rest cool area.

$>$ Use ventilation / extraction and air conditioning systems notify if they are not working.

$>\mathrm{Be}$ aware of emergency/first aid procedures associated with heat related illness.

$>$ Be aware of heat illness risk factors.

4.2.4.2. Noise: In hospitality industry, noise can be found in dishwashing areas, in the laundries, beside equipment in ships cruise and the noise of music for bars and nightclubs. When noise exposure exceeds the upper exposure limit $\mathbf{( 8 5}$ $\boldsymbol{d B})$ will be harmufull. Noise reduction by technical means, such as barriers, enclosures and sound-absorbent covers, damping or insulation is essential. It is preferable to organize work to reduce noise by limiting duration and intensity of exposure- and consider appropriate work schedules with rest periods (Work Safe, 2009).

\subsubsection{Biological Hazards:}

Workers may be at risk of contact with body fluids such as blood, vomit or feces. Also, workers at laundry are exposed to body fluid from soiled clothes. Exposure to infected blood and body fluids occured if sharp contaminated objects puncture workers skin or during cleaning bathrooms is possible. Standards precautions assume that all bodily fluids are contaminated. Both human blood and body fluids are considered as infectious with human immunodeficiency virus (HIV), hepatitis B (HBV), and other pathogens born in the blood. Kitchen can be a source of growth of bacteria if proper food, personal hygiene and recommended food practices and procedures are not followed.

To reduce the risk of biological hazards: (Work Safe, 2014).

Use personal protective equipment such as disposable gloves.

$>$ Look before you clean. Do not put your hands directly in trash cans/ containers.

Keep bag away from the body when 
emptying trash cans.

> If a syringe/needle is located, handle it as if it were used.

$>$ Never handle syringe with needle end, handle it with barrel end.

$>$ Place the needle in puncture resistant container (special colored red containers)

$>$ Do not throw syringe disposal containers into dumpsters.

> Use garbage bags or specially marked laundry bags to separate soiled items.

$>$ Proper storage of food. Always follow food and safety precautions at the kitchens.

\subsubsection{Stress Hazards:}

Occupational stress is prevalent in the hospitality industry due to workloads, shiftwork, job insecurity, low pay, irregular working hours and discrimination. Violence, harassment and stress are not specific to any job. However, they are common in industries that provide customer services, such as in hotels and restaurants. They can lead to physical and psychological injury (Barly et al., 2017).

4.2.6.1. Violence: Incidents of violence includes attempt or actual assaults, any threatening statement or behavior toward an employee by anyone. In another words it includes any threatening statement or behavior which gives reason to believe a worker is at risk of injury. For example, at work place, staff may need to serve customers under the influence of drugs or alcohol. Also, workers may face risks during walking to or from a bus stop on their way to work, particularly at late hours.

\section{To reduce violence at the workplace:}

Employers need to take action to prevent workplace violence: find if there is a risk of workplace violence; implement procedures to eliminate or reduce workers' risks. Educate workers about the dangers of violence at work and the appropriate responses to violent behaviors or threats (Chris, 2013).

4.2.6.2. Harassment: Is any inappropriate conduct, comment, display or action by a person that could constitute a threat to another worker's health or safety. The mistreatment of a worker can be due to their race, faith, religion, color, sex, sexual orientation, marital status, family status, disability, physical size or weight, age, nationality or place of origin. This type is strictly prohibited as it affects the worker's 
psychological or physical well- $>$ Options for controlling hazards being badly. Examples of personal harassment include verbal or written abuse or threats, insulting jokes or gestures, personal ridicule or malicious gossip, work sabotage and vandalism of personal property.

\section{To reduce harassment at the workplace:}

Employers should develop and implement a written harassment policy that meets the requirements in the legislation and ensure that employees are not subjected to harassment as a result of any work situation (Work Safe, 2014).

\section{5-Hazards Prevention and Control}

Effective control measures to protect employees from hazards in the workplace, prevent accidents, illnesses and incidents, reduce or eliminate threats to safety and health. It also helps employers to provide safe and healthy working conditions for workers.

\section{Employers should control and} prevent hazards by the following: (OSHA, 2016).

$>$ Workers often have the best understanding of the conditions that create hazards, so they should be involved and insights on how hazards can be controlled.

should be identified and assessed.

Immediately remove or monitor all serious risks (hazards that cause or are likely to cause death or physical harm).

D Employers should select the most feasible, effective and permanent controls.

Choose controls according to a hierarchy of controls that illustrate engineering solutions (including removal or replacement) first, followed by safe work practices, administrative controls, and finally PPE.

$>$ Use a hazard control plan to guide the selection and execution of controls and implement planspecific controls.

$>$ Create strategies for the safety of workers in emergencies and nonroutine operations.

$>$ Assess the efficacy of current controls to assess if they continue to provide security or whether various controls can be more successful.

Review new technologies to make them more protective, reliable and less expensive. 


\section{6-Safe Work Procedures}

Safe work procedures are guidelines on how to properly do the work. Information about hazards and what to do to eliminate or reduce risks is written for the safety of the workers. Not all tasks require a written safe work procedure. When training workers, it may be sufficient to address safety issues verbally. In order to decide whether a written protocol is needed, consider the following: How serious would be the consequences of an accident? How often does the task take place? How complicated is that task? Written safe work protocols are recommended for medium to high risk hazards activities and complicated tasks, in order not to skip important steps, regularly done tasks, to prevent shortcuts less repetitive tasks if any (Work Safe, 2009).

The process of developing a written, safe working procedure for a hazardous task includes the following steps: -Determine the overall task that requires a safe working procedure -Split the mission down into its necessary steps- Identify the risks associated with each step and ways of eliminating or minimizing those risks to workersWrite the safe work procedure ( the list of actions that workers must do when performing the task)- Post the procedures prominently at the locations where the tasks are performed or next to the equipment used for the tasks. Supervisors and managers will find them helpful in training workers how to do their jobs safely. Workers are then responsible for the procedures- Lists the required PPE when writing safe work procedures should be available. Not only does the procedure need to identify when to wear the PPE, but the worker also needs to be trained in its limitations, how to maintain and store it, and who to contact when it needs to be repaired or replaced (Work Safe, 2014).

Tasks that may require written safe work procedures in the hospitality industry include: disposal of hot oil, handling garbage, cleaning of blood and other body fluids, cleaning of bathrooms, ovens or swimming pools, and turning of mattresses. Certain specific tasks and situations often require written safe work procedures; for example, locking of equipment, preventing aggression and harassment in the workplace, working alone or in isolation (Work Safe, 2009).

\section{Conclusionand Recommendations}

Many of the activities in hospitality industry involve various health hazards 
for workers. It is a must to be sure that people's safety and health is not at risk. So, there is a need to recognize different risks at work place to ensure a safe and health working environment in the hospitality sector. Everyone involved in this business has safety and health duties and responsibilities, which are clearly outlined. It is recommended that any enterprise or establishment in hospitality sector should set up a risk assessment and control measures for different health hazards at the workplace.

\section{References}

1- Barry SL, David HW, Sherry LB, and Rosemary KS (2017): Occupational Stress. In: Occupational and Environmental Health, Publisher: Oxford University. University Press Scholarship Online. Oxford Scholarship Online. November 2017. DOI:10.1093/oso/9780190662677.001.0001

2- California Workers' Compensation Information System (WCIS) (2016): Workplace Injuries in Hotel Housekeeping in California. Department of Industrial Relations. Available at: https:// www.dir.ca.gov/OSHSB/documents/HotelHousekeeping-Musculoskeletal-InjuryPrevention-dr4.pdf.

3- Global Hotel Industry (2018): Global hotel industry market size 2014-2017. Available at: https://www.statista.com/statistics/247264/totalrevenue-of-the-global-hotel-industry/

4- Global Hospitality Portal (2016): What are the 5 Different Sectors of Hospitality Industry?

Available at : https://www.soegjobs. com/2016/09/07/different-sectors-hospitalityindustry/

5- Global Travel and Tourism Industry (2018): Statistics \& Facts by Statista Research
Department. Available at: https://www.statista. com/topics/962/global-tourism/.

6- Chris C (2013): Four Types of Workplace Violence. HUMAN RESOURE MANAGEMENT \& COMPLIANCE. Available at: https:// hrdailyadvisor.blr.com/2013/12/27/4-types-ofworkplace-violence/

7- Henderson JC, Shufen C, Huifen L and Xiang LL (2010): Tourism and Terrorism: A Hotel Industry Perspective. Available at: https://core.ac.uk/ download/pdf/154828459.pdf.

8-Hospitality (2014): A guide to health and safety. Department of labour, Republic of South Africa. Available at: http://www.labour.gov.za/DOL/ documents/useful-documents/occupationalhealth-and-safety/hospitality-a-guide-to-healthand-safety-1.

9- Hospitality Industry (2008): Work place Safety; Orientation \& training guide: Available at: https:// www.lni.wa.gov/Safety/GrantsPartnerships/ SHIP/awardees/WaRestaurantAssociation/ HospitalityIndustryOrientationTrainingGuide. pdf.

10- Occupational Safety and Health Administration (OSHA) (2016): Recommended Practices for Safety and Health Programs. Available at: https://www.osha.gov/shpguidelines.

11- Oxford Dictionary (1998): Available at: https://en.oxforddictionaries.com/definition/ hospitality.

12- Peter N (2017): What Are The 4 Segments of The Hospitality Industry? Available at: h t tps: // www.hospitalitynet.org/ opinion/4082318.html.

13- Safe Hospitality (2014): Safety, Health \& Welfare in Hotels, Restaurants, Catering \& Bars. By health and safety authority. Available at : https://www.hsa.ie/eng/Your_Industry/ Catering and.../The Law/.

14- Sally JS (2017): Hazards in food \& beverage manufacturing are found in many workplaces. Available at: https://www.ishn.com/ articles/106363-hazards-in-food-beveragemanufacturing-are-found-in-many-workplaces. 
15- Sarah RL, Alan MH and Pricilla AM (2018): On cooking, A textbook of culinary fundamentals. fifth edition update. Available at: https://www. scribd.com/document/392111410/On-CookingFifth-Edition-Update-Sarah-R-Labensky.

16- Srivastava M (2017). Potential health hazards of workers in hospitality industry. Internat J Appl Home Sci, 4 (7 \& 8): 617-22

17- Travel, Tourism and Hospitality (2018): Statistics and Market Data on Travel, Tourism \& Hospitality: Available at : https://www.statista. com/markets/420/travel-tourism-hospitality/

18- Wayne P (2015): occupational health safety in the hospitality industry. Available at: https:// pjtaccountants.com.au/author/wpatten/ occupational-health-safety-in-the-hospitalityindustry/

19- Work Safe BC (2009): Health and Safety for Hospitality Small Business: Work Safe BC; the Workers' Compensation Board (WCB) for British Colombia. Available at:

https://www.worksafebc.com/en/resources/ health-safety/books-guides/health-and-safetyfor-hospitality-small-business?lang=en .

20-Work Safe S (2014): Health and Safety for Hospitality Small Business: Work Safe Saskatchewan; Saskatchewan Workers' Compensation Board. Available at: https://www.worksafesask.ca/wpcontent/uploads/2013/12/Hospitality. Document_ FINAL_web_14.07.15.pdf. 
